\title{
Experience of the Joint Institute for Nuclear Research as an Example of International Scientific Cooperation in the Frame of Sustainable Development
}

\author{
Tataina Strokovskaya \\ Department of Sociology and Humanitarian, State University “Dubna”, Dubna, Russia \\ Email address: \\ t.e.strokovskaya@gmail.com
}

\section{To cite this article:}

Tataina Strokovskaya. Experience of the Joint Institute for Nuclear Research as an Example of International Scientific Cooperation in the Frame of Sustainable Development. International Journal of Economics, Finance and Management Sciences.

Vol. 5, No. 5, 2017, pp. 246-250. doi: 10.11648/j.ijefm.20170505.13

Received: July 31, 2017; Accepted: August 21, 2017; Published: September 19, 2017

\begin{abstract}
The Joint Institute for Nuclear Researches (JINR) in Dubna has become the real space of international cooperation of scientists and a field of intellectual collaboration, co-influence of different cultures. JINR was and is one of the basic elements of sustainable development in Central Europe since the soviet period. Its activity in Dubna is the evidence of the fact that the result of joint efforts of peoples, governments and scientists produces synergetic effect in science, and in the process of international dialogue at all levels. The history of JINR is the way from a secret organization through recognition of the necessity for international interaction in a certain field (science) to the unique, integrated international environment, where the common human principles and values dominate, while the national peculiarities carefully preserved at the same time. In essence Dubna and JINR today are an example of inter-cultural communications covering all levels: from inter-governmental to interpersonal communication.
\end{abstract}

Keywords: Science, Collaboration, Development

\section{Introduction}

The goal of this article is to demonstrate how the cooperation in large and long-lasting international projects becomes the element of sustainable and progressive development of the European space, improves the security and stability of the integrated environment. The issue based on content analysis and comparative method in the study of the sources of various genres: memoirs, official documents, containing information on the career and everyday routine of foreigners in Dubna. A comparison of the fundamental targets of State research programs and the personal goals of foreigners integrated into different social reality, helped to clarify the role and place of humanitarian initiatives in international strategy. The activity of the Joint Institute for Nuclear Researches in Dubna is the evidence of the fact that the result of joint efforts of peoples, governments and scientists produces synergetic effect either in science and culture. The process of international dialogue at all levels assists to the successful, save and dynamic development such special sphere as nuclear technology is.

V. I. Veksler in the USSR (1944) and E. M. McMillan in the USA (1945) independently discovered the principle of phase stability in the particle accelerators. Soon, a construction of synchrocyclotrons begun in Berkeley (USA) and in Dubna (USSR). The largest at that time proton accelerator - synchrocyclotron - had been initiated by Igor Kurchatov, a member of the USSR Academy of Science. It has been successfully commissioned 120 kilometers away from Moscow, on the bank of Volga River in Dubna-town. By the mid 1950's it became obvious that the nuclear science should not be restricted by the secret laboratories and that only extensive cooperation could ensure the active development of this fundamental field. In 1954 near Geneva CERN - the European Organization for Nuclear Research has been created for consolidation of the efforts of the Western European countries. In 1956 in Dubna 11 countries consolidated their scientific and financial resources with the aim to study the fundamental properties of matter, signed the agreement on foundation of the Joint Institute for Nuclear 
Researches. In March 1956, the members of the Joint Institute for Nuclear Research became Albania, Bulgaria, Hungary, the German Democratic Republic, the People's Republic of China, the Democratic People's Republic of Korea, Mongolia, Poland, Romania, the USSR and Czechoslovakia. In September 1956, the Agreement on the Formation of JINR was signed by the representative of the Government of the Democratic Republic of Vietnam.

The idea to join and coordinate the efforts and resources of various countries in the field of fundamental researches was an innovative for that time. It became a successful example of international communication and integration in Europe. The first Director of JINR was D. Blohintzev, and Vicedirectors V. Votruba (Czechoslovakia), and M. Danysh (Poland). Among the originators of the Institute were such prominent physicists as Kurchatov and Efremov (USSR), L. Jánossy (Hungary), H. Pose and H. Hertz (Germany), A. Soltan and L. Infeld (Poland), V. Petrzilka (Czechoslovakia), G. Nadzhakov (Bulgaria), H. Hulubei (Romania). Many of them later chaired the major research centers in their native countries. International groups of Dubna physicists from JINR made nearly half of the discoveries (about 40) in the field of nuclear physics registered in the USSR.

To honor the outstanding contribution of JINR scientists to the modern physics and chemistry the IUPAC General Assembly (Union of Pure and Applied Chemistry) named the synthesized in Dubna $105^{\text {th }}$ element of Mendeleev's Periodic System "DUBNIUM" [1].

\section{Methodology}

\subsection{Content Analysis and Comparative Method}

The issue based on content analysis and comparative method in the study of the sources of various genres: memoirs, official documents, containing information on the scientific researches and everyday routine of foreign professionals and their families abroad. The method of content analysis of scientific correspondence, made use of archive and not popular published materials was applied. A comparison of the fundamental targets of State scientific and educational strategy and the personal goals of foreigners integrated into different social reality, helped to clarify the reasons and place of humanitarian initiatives in international policy.

\subsection{The Scientific Novelty}

The author's attention is focused also on the analysis of policies and actions by the authorities in the field of interethnic interactions and adaptation, and on an attempts and ways of self-expressions by ethno-cultural communities. The author intends to analyze the methods of integration of the national community from Eastern Europe, included socialist countries and the soviet citizens of Dubna-town in the context of the development of the common European space in the middle of XX century. The scientific novelty and relevance of the chosen subject, according to the author, lays in the fact, that the historical experience of the methods of cooperation between the state and society in the field of science has not yet been analyzed from the point view of the process of international image making by the state or shaping public opinion outside the state, as well as from the point of view of national identity or sustainable development.

\section{Results}

\subsection{Foreign Specialists in Dubna and JINR}

The structure and legal status of JINR reflect its special position as the organization of international cooperation. Geographically the Institute is located in Russia. Yet this scientific institution holds intergovernmental status and is managed by an international authority complying both with the RF legislation, international legal norms and its own Charter signed by the Plenipotentiaries of the governments of the Member States. The Committee of Plenipotentiary Representatives (CPR) of the governments of the Member States is the supreme body governing the Institute. The Scientific Council and Finance Committee realize their activities annually under control of the Committee of Plenipotentiaries pursuant to the adopted Regulations. It consists now of 18 appointed members from the Member States; 25 members elected by CPR. Specific and required characteristics of work in the international scientific environment created in JINR are high quality of scientific results, flexibility of the researchers' minds, their readiness to learn something new, maintaining the Institutional spirit of free scientific creativity based on the openness to contacts and readiness to maintain dialogue, cultural and ethnoconfessional tolerance. It can be stated using modern lexicon that Dubna was and remains an integrated pan-European space, where multiculturalism is a reality and necessary element of international cooperation.

The peculiarities of working process and the details everyday life of the foreign specialists in Dubna are reflected the book "Golden Cage Tales" by François Lehar, a Czechoslovakian and later French experimental physicist. He had been working in JINR back in 1960's. After the troops of socialist community entered Czechoslovakia in 1968 he moved to Western Europe taking French citizenship. The last years of his life he lived and worked in Prague. The book has been written and published in 1995 due to the insistence of F. Lehar's colleagues from JINR [2]. There are reminiscences by the other employees of JINR and the data from my own archive documents added to the of Lehar viewpoints when touching on the period from the second half of 1970's to the 1980's. They were published in the book "Times and the people" [3]. Specific environment of Dubna-town made the town a place where communication between the citizens of different countries, primarily Central and Western European, could be free and easy. Those were not only the scientists. This community also included their families, children who studied in common secondary schools of Dubna-town and made friends within the children of Soviet families. In each 
class of any Dubna school several children from Poland, Romania, Germany, Hungary, Czechoslovakia, Bulgaria also the Cubans, the Vietnamese the Mongols studied. For instance, in the elementary school where I studied the, the Hungarians and the Bulgarians studied in the same class, in the secondary school I studied together with the Czechs, The Hungarians and whose parents worked in JINR.

For the foreign specialists JINR was a special environment. During the years when the Socialist community of countries existed, Dubna was considered as an "academic bridge to Europe". Here physicists from the different countries of Central Europe communicate with the Western scientists easier. That is why many of them strived to come to Dubna. For example, a young Czech physicist Frantisek Lehar, graduate of Charles University in Prague, was eager to get to Dubna hoping to get rid of the watchful eyes of the communist party organization of his alma mater. Nevertheless it would be a mistake to say that Dubna was an "island of freedom" within the USSR. There were either Communist party control, notorious "first department" (KGB special department), various limitations in JINR. For instance, for many Soviet employees to invite a foreigner for dinner at their own place was forbidden. Before Lehar left his University the faculty party committee advice him to get acquainted with the life and efforts of the Soviet people building communism [4]. In other words this trip was supposed to become a good maturing lesson for excessively independent young man.

In general, the foreigners had certain privileges, but there were many limitations, especially in relation to the traveling. You had not only to get a permission of Visa service, but also to approve the trip details in the Institute International Department. When traveling by car, you could not stop on the way. The nearest town $20 \mathrm{~km}$ down Volga-river - Kimry - was totally prohibited for the visiting, and it was impossible to get a permition [2, 17]. The foreigners from Western Europe could travel during their vacations only with a guide. The citizens of socialistic countries could travel on their own, but only to the certain list of cities and often only using certain transport. Foreign colleagues were often asked about their life in their native countries, and sometimes the information from private conversations contradicted the official information. F. Lehar notes: "it turned out that historical facts were understood differently. Few of the Soviet people believed that the cultural development of many of the socialist European countries were traditionally connected to the Western Europe, and that communist system was completely strange to the most people of those countries, and their life level was much higher. The influence of democratic past was different everywhere, and everyone meant something different when speaking of the democracy." $[2,19]$

\subsection{Peculiarities of the Everyday Life in Dubna in Soviet Period}

In the middle of the 60-th such phenomenon as "deficite" (lack of the goods) were spread in USSR. So On the delivery days (that was the name for the days when goods were distributed to the stores) women used to go away from their workplaces for shopping and stand in the lines. It was not necessary to look for your matching size, people took what they were offered, and if it didn't fit, you could change it later among the colleagues. In 1970-1980 the system of "cards" was introduced; those were the card for buying the imported goods. The foreigners used to buy photo cameras, watches, records, vinyl disks and books in the Soviet Union. In the mid 1960's foreigners could buy a car in native embassy in Moscow. Such purchase was advantageous, but in the mid 1970's it was stopped. Wives of the foreign employees buy whatever they were short of during the vacancies in their native countries. Often they took requests from their Soviet friends. That is why in comparison with other cities of the USSR, women in Dubna were dressed fashionably and elegantly, in the European style. For instance, women in Dubna started wearing pants, using accessories as part of business suits and using French perfume and make-up much earlier that in the other part of the Soviet Union. Many Dubna school-girls of the 1960's1980's in March gladly created and pinned their school uniform "martenitsi" (Bulgarian decorations). The schoolchildren of Dubna knew that their foreign friends celebrate Christmas, which, by the way, was accepted not as a religious holiday but as one of the European national holidays. The schoolchildren of Dubna contacted with the European culture of everyday life through games, exchanging of coins, stamps, tested national delicacies brought from home. In Dubna national schools - Czech, German, Polish and Bulgarian - were organized where the foreign children studied their native language, history and culture. Obviously, the language of international communication was Russian language. Foreign children participated in the common school and class activities: excursions and trips to the museums and exhibitions, practiced sport and tourism.

Foreign professionals who lived and worked in Dubna, whether they were willing or not, represented Europe in the eyes of the Soviet citizens. Staying outside their countries they tried to preserve their national culture and get their colleagues acquainted with it. Several national associations existed in JINR which actively communicated with each other, organized joint travels, picnics, national festivals. So a field of inter-European communication was formed in Dubna. The Czechs, the Romanians and the Hungarians who worked in JINR maintained very good relations with each other. When the Soviet troops entered Hungary in 1956, many Czech and Hungarian specialists from JINR, who had such chance, emigrated to the West, including the USA. The same happened in 1968 as a reaction to the incident in Czechoslovakia. Polish association had its own library, which was frequently used also by the people from other associations because even in 1960's in Poland a number of books was published which were never published anywhere else. National festivals were an important part of intercultural communication for JINR employees. Such holidays usually were celebrated in the Scientists Club or City Culture Center and included national food and drinks and concert 
represented by a national movie or music and dances.

Lehar wrote about the celebration of The Day of Czechoslovakia celebrated on May 9. The Czech community wanted to organize something extraordinary and after long discussions it was decided to organize in the town an entertaining intellectual competition with the questions devoted to Czechoslovakia. In order to make the game interesting, they needed prizes. So the organizers sent letters to different Czech companies explaining what their intention was, and asking to send samples of their products. The response was unexpectedly active. Many plants and factories sent their gifts of the highest quality and in large quantities. The gifts were accompanied by the letters and invitations for the scientists from Dubna to visit the enterprises and talk to the workers on the objectives of the scientists in Dubna. "The Czechoslovakian embassy received for the Organizing Committee Czech crystal, sunglasses, pencils, pens, shirts, smart toys, dolls that talked and even walked, scarves, ties, umbrellas, porcelain and expensive imitation jewelry. It was a real representation of the Czechoslovakian industry. The main idea was to show to the Russian friends what Czechs produce, what traditions they have and what quality they ensure" [2, 27] As a result the real vivid and interesting celebration was hold which was remembered by the people of Dubna.

\subsection{Sustainable Development Today}

JINR is now a large multi-branch international scientific centre with activities incorporating fundamental research of the structure of matter, development and application of high technologies, and university education in the relevant fields.[5] To develop international cooperation by attracting young scientists, the University Center of JINR was established in March 1991. It focuses on upgrading skills of students of universities of Russia and high schools of other countries on the technical basis of JINR. This helps to engage highly qualified personnel to work in the JINR's laboratories and the scientific centers of the countries-members.

One of the components of the activity of the University center is the cultural adaptation of foreign specialists assigned to JINR through the study of the Russian language in educational courses [6]. JINR management organized the Russian language courses for foreign specialists depend on the modern challenges. English language gradually became the predominant language of communication for the new generation of participants of international projects. However, the level of English skills of common people and most of the stuff of organizations supporting the functioning of the scientific community in Russia was 1) remarkably different, and 2) in many cases inadequate, which complicate the daily life of foreign employees and their families. The specific benefit of the course is that providing the opportunity to learn the Russian language as soon as possible, to the extent necessary for career and comfortable life in the country, classes are accompanied by a series of lectures on Russian culture and art, as well as the key points of Russian history, peculiarities of behavior and everyday life, which are unusual to foreigners. It is also important that the JINR member states pay for their employees, while for the trainees themselves the course is voluntary and free of charge. Studying of cultural history and various influences on the country's culture provides for understanding of a modern world view and the way of thinking characteristic of native speakers. Language as main communication tool for the native speakers, and the means of transmission of cultural values reflects changes of the cultural model. The language itself plays the role as structuring component of the mental model fixing shifts and transformations of the community's mentality in vocabulary, grammar, and often in phonetics. That is why the knowledge of cultural history of the country of the studied language helps grow familiar with the concepts of native speakers and imbibe their way of thinking, i.e. cross the border between "Insiders" and "Outsiders" and adapt to the mental field of the foreign language. [9]

The identified need of foreign employees in some adaptation to the cultural environment and everyday customs they faced abroad was additional motivation for organizing Russian language courses. For example, certain special features of paraverbal communication make it difficult to understand the Russians [8], such as the high tone of voice, assertive intonation which is often perceived as aggressive, the loud manner of speaking (for Czechs and Romanians, Japans), the "weeping" tone (for the French), the high rate of speech (Mongolians). The desire to finish the sentence instead of the communication partner astonishes the Germans, Bulgarians and Japans, who take such manner of behavior as ignorance. It should be added that, for most foreigners from CIS countries and states of the Central Asia, the Russian language is still preferable to the English. During the last years the interest to the Russian language is rising in China, which is now an associated member of JINR too. For example, in 2011, 2012, 2013 Chinese universities sent to the University "Dubna" large groups of students to study the Russian language. Globalization processes make relations between nations or even civilizations become more and more influential factors of global development. Such notions as cultural or mental model, world view, semiotic or structural differences between cultures gain not only scientific but also practical importance in the sphere of international relations and cross-cultural contacts. [9] Since 2009, in Dubna tradition of celebrating the days of Slavic alphabet and culture was renovated. In the middle of May there are thematic concerts, seminars, church services, a children's party and a festival procession over the town. Schoolchildren, teachers, national Slavic associations and Orthodox community take part in celebration. The libraries of the city prepare specialized book' exhibitions, art objects of the city provide a place for thematic expositions. Since 2014, the University of Dubna has joined the celebration, organizing a number of scientific, educational and literary events "Slavic Bouquet". For instance, in 2016, within the framework of the "Slavonic Bouquet", the report and slide-show on Alfons Mucha's art was presented. 


\section{Conclusion}

In essence Joint Institute for Nuclear Researches (JINR) in Dubna today is an example of inter-cultural communications covering all levels: from inter-governmental to interpersonal communication. Its history demonstrates how the cooperation in the international research centre formed the wellintegrated international space, where global human values dominate and at the same time the national features are carefully preserved. As a space of collaboration, co-influence and synergetic effect JINR is one of the basic elements of sustainable development in Central Europe.

\section{References}

[1] Sissakian Alexej. "Report by JINR Director at the Ceremonial Meeting of the JINR Committee of Plenipotentiaries and Scientific Council dedicated to the $50^{\text {th }}$ anniversary of JINR on 26 March 2006". Available at http://www.jinr.ru/about/ [Date of quotation 12.02.1017].

[2] Frantishek Lehar "Golden Cage Tales". Dubna. 1997. 85p. ISBN 5-85165-468-6.

[3] Collection of articles "Times and me. Remembrances". Publishing by Dubna State University. Dubna 2004. ISBN 589847-134-0. Editor Ivan Shimon. 152 p. Chapter by Strokovskaya pp. 118-123.

[4] Alexader Rastorguev. "Dubna, which is with You" Dubna 2005. Available at www.proza.ru (2007) Publishing license №2512030078, http://www.proza.ru/2007/07/26-137. [Date of quotation 12.02.1017].
[5] Strokovskaya T. "The international research centre as a field of intercultural communication in Soviet period: two dimensions." pp. 227-238 In "From classroom to workplace: advances in applied linguistics." Edited by Emilia Wasikiewicz-Firlej and Hadrian Lankiewicz. PWSZ im. S. Staszica w Pile. Pila. 2013. ISBN 978-83-62617-23-4, Piła: 2013, 238p.

[6] http://ucnew.jinr.ru/ru/russian [Date of quotation 20.08.1017].

[7] Strokovskaya T. "Russian Language in the Perception of Foreign Employees of Joint Institute for Nuclear Research" p. 155-163 in "CULTURE AND CREATIVITY IN DISCOURSE STUDIES AND FOREIGN LANGUAGE PEDAGOGY" PWSZ im. S. Staszica w Pile. ISBN 978-8362617-23-4, Piła: 2013.

[8] Collection of materials of the IV International Scientific and Practical Forum "Languages. Cultures. Translation". July 310, 2016. Materials: electronic edition M. "Publishing Forum" 2016, ISBN 978-5-00091-216-4. 282 p. Strokovskaya T. "Russian language for special purposes in the context of intercultural communications". pp. 188-199. Cite p. 193.

[9] Informed teaching - premises of modern foreign language pedagogy. Piła: Wydawnictwo PWSZ im. S. Staszica w Pile. Pila. 2011. ISBN 978-83-62617-10-4. S. 82-89, Citep. 84, 82.

[10] CONFERENCE PROCEEDINGS MEZINÁRODNÍ KOLOKVIUM BEZPEČNÁ SPOLEČNOST 2017. České Budějovice, 30 - 31 března 2017 Publisher: Vysoká škola evropských a regionálních studií / College of European and Regional Studies. Czech Republic. 2017. Vysoká škola evropských a regionálních studií ISBN 978-80-7556-017-9. ISSN 2533-6223. 88c. 